\title{
Design and Year-Long Performance Evaluation of a Pump as Turbine (PAT) Pico-Hydropower Energy Recovery Device in a Water Network
}

\author{
Daniele Novara * and Aonghus McNabola (iD
}

Citation: Novara, D.; McNabola, A. Design and Year-Long Performance Evaluation of a Pump as Turbine (PAT) Pico-Hydropower Energy Recovery Device in a Water Network. Water 2021, 13, 3014. https:// doi.org/10.3390/w13213014

Academic Editors: Helena M. Ramos and Sajjad Ahmad

Received: 27 September 2021

Accepted: 26 October 2021

Published: 27 October 2021

Publisher's Note: MDPI stays neutral with regard to jurisdictional claims in published maps and institutional affiliations.

Copyright: (c) 2021 by the authors. Licensee MDPI, Basel, Switzerland. This article is an open access article distributed under the terms and conditions of the Creative Commons Attribution (CC BY) license (https:/ / creativecommons.org/licenses/by/ $4.0 /)$.
Department of Civil, Structural \& Environmental Engineering, Trinity College Dublin, D02 PN40 Dublin, Ireland; amcnabol@tcd.ie

* Correspondence: novarad@tcd.ie

\begin{abstract}
Despite the existence of a vast scientific literature on the subject of hydraulic energy recovery from water pipelines by means of micro- and pico-hydropower using pumps as turbines (PAT), such technology has found a very limited application thus far in practice. In fact, the selection of a pump as turbine for a specific site is a matter of nontrivial trade-offs between a variety of technical and economic parameters and this aspect has not been sufficiently captured and integrated into a reliable, proven, and practical selection methodology available to designers and practitioners. Hence, a multi-objective PAT selection software was developed and utilized to design a $3 \mathrm{~kW}$ energy recovery installation at a rural Irish water network. The performance of the scheme was monitored over 13 consecutive months, resulting in the generation of nearly 16,000 kWh of electricity and validating the output from the PAT selection software.
\end{abstract}

Keywords: pump as turbine (PAT); best efficiency point (BEP); decision support software; field evaluation

\section{Introduction \\ 1.1. Generalities and Applications}

Energy recovery from existing water pipelines through micro-hydropower (MHP), (i.e., hydro power with installed capacity less than $100 \mathrm{~kW}$ ) is a widely investigated practice that has found a limited degree of practical application to date due to several factors such as the large acquisition cost of miniaturized conventional hydro turbines and the lack of well-established design guidelines [1]. Indeed, this is also true to a greater extent when considering pico-hydropower (PHP) applications in water pipelines, where the acquisition costs present an even greater challenge, however, the number of potential PHP opportunities is very large [2].

The principle behind MHP or PHP in water pipelines is to recover a portion of the energy being dissipated in throttling valves along a certain water network and convert it into electricity by means of a hydraulic turbine. In fact, in almost any drinking water or irrigation network, irrespective of the way used to pressurize the water (gravity or pumping), some portions of the pipe network will need to reduce such pressure, unless the terrain is entirely flat, and the demands and head losses are entirely uniform throughout the network. While traditionally, pressure reduction is carried out using pressure reducing valves (PRV) or control valves, it is possible to use a hydraulic turbine in parallel to these, instead, to recover a portion of the dissipated pressure and convert it into electricity [3-5]. This recovered electricity can either be used locally or exported to the grid. In order to reduce the installation cost, the use of a reverse-running centrifugal pump, also known as pump as turbine (PAT) has been suggested instead of conventional hydraulic turbines [1,6,7]. Such devices are generally inexpensive, easy to source, repair, and adapt for installation within wholly pressurized conduits [7-9]. PATs are hydraulically similar 
to a Francis turbine, but with rigid geometry and backward-curved blades, leading to poor part-load performances when compared to a conventional hydro turbine (e.g., Pelton, Francis, Kaplan, Crossflow). Furthermore, their peak efficiency is usually lower than a custom-designed water turbine since PATs are standardized pieces of equipment that were originally designed and optimized for different applications, [6,10,11].

\subsection{PAT Selection Challenges}

While a significant amount of scientific literature exists on different aspects of PATs such as turbine performance, installation cost, turbine control, and economic parameters, only a limited number of comprehensive PAT selection tools encompassing all the previously mentioned aspects are available at the moment [12]. The development of such tools is particularly important considering the many thousands of hydraulic pumps that can be used as PATs that are currently on the market, and therefore a multitude of units of different make and geometry could potentially generate a certain amount of power at any given potential hydropower site [13]. However, since the vast majority of PATs have only been experimentally tested in pump mode, their performance in reverse mode must therefore be estimated via either mathematical models or computational fluid dynamics (CFD) [14-18]. The uncertainty related to these methods can result in a severe overestimation of the PAT performance. Furthermore, maximizing the power output alone may not always be the key parameter for PAT selection. In fact, in cases when the PAT is expected to work off-grid in a standalone application, having a too large power output may be equally an issue, which must be addressed with additional dissipation devices (PRV or electric dump resistor), thus driving up the installation cost [19].

Furthermore, the design of a PAT scheme and the exact pump selection is also the results of trade-offs between sometimes contrasting technical and economic parameters such as those listed in Table 1 [12]. An example of contrasting design parameters is when the designer of a PAT energy recovery site needs to maximize the yearly energy yield from that scheme and at the same time minimize the required investment. Given the vast number of off-the-shelf available PATs, the designer will be faced with multiple possible choices of pump for that very site and realistically smaller and less expensive PATs will result in a lower yearly energy yield. At the same time, PATs with a larger nominal power output may be able to recover a greater amount of energy, albeit at an increased capital cost.

Table 1. Summary of possible technical and economic design parameters relevant to a PAT energy recovery installation.

\begin{tabular}{ll}
\hline & \multicolumn{1}{l}{ Maximization of energy generation over a certain period of time } \\
\cline { 2 - 2 } Technical aspects & $\begin{array}{l}\text { Maximization of power output } \\
\text { Ensuring that the flow and pressure across the network is not disrupted by } \\
\text { the need to provide water for firefighting purposes) }\end{array}$ \\
\cline { 2 - 2 } & \begin{tabular}{l} 
Maximization of the $\mathrm{CO}_{2}$ savings over time \\
\hline System readiness under varying operating conditions (e.g., flow transients)
\end{tabular} \\
\hline & \begin{tabular}{l} 
Compliance with the (eventual) space limitations given by the site \\
\hline Minimization of the investment cost
\end{tabular} \\
\hline & $\begin{array}{l}\text { Minimization of maintenance cost } \\
\text { Minimization of the project payback time }\end{array}$ \\
\hline
\end{tabular}

It is worth noting that the value attributed to the parameters displayed in Table 1 will be variable and subject to the judgement of the designer responsible for the installation and the managers of the pipe infrastructure. Therefore, the issue of selecting the most appropriate PAT for a determined site is an issue of multi-objective optimization where 
the relative weight of the different techno-economic parameters leading to the final choice of equipment is highly dependent on the context and the organizations involved in the project.

\subsection{Review of Existing PAT Selection Methods}

A number of PAT selection methodologies are available in the literature, several of which are centered around the measured performances of a limited number of PATs whose impeller diameter or speed are modified to fit the average characteristics of the selected site by means of the affinity laws of turbomachinery [20-22]. The main drawback of these approaches is their dependency on the performances of a small set of machines from a determined manufacturer, which are not representative of the thousands of PATs of different sizes and makes available on the market. Additionally, the use of affinity laws introduces a significant source of uncertainty, and in many cases, the effect of variable hydraulic conditions has not been considered [20,23]. However, it is common for drinking water networks to present highly variable daily and seasonal profiles of available head and flow rate [24].

The PAT design methodology named the variable operating strategy (VOS) has the advantage of considering the flow and head variability at the chosen energy recovery site $[25,26]$. In order to cope with this, the authors proposed the use of either an automated bypass in parallel to the turbine (hydraulic regulation, HR), or the adoption of a variable speed drive to change the speed of the PAT (electric regulation, ER) $[25,26]$. Additionally, this design strategy acknowledges that the amount of electricity generated over time is not the only factor to be considered when selecting a PAT. Instead, the authors recommend choosing the exact turbine model according to the results from an optimization algorithm, which maximized a composite function that includes energy maximization, payback period, effectiveness, and reliability [27]. However, the main drawback of this methodology is the lack of practical applicability since it describes the principles behind PAT selection, but does not offer a practical way of selecting a machine from the catalogues of pump manufacturers. Additionally, the relative weights of the singular elements of the global composite parameter to be optimized (capability, effectiveness, reliability) have not been developed in an analytical way and therefore deprive the results of the analysis of rigor and repeatability.

An additional PAT selection methodology has been published by Barbarelli et al. [28], which does not contain an element of optimization, but is rather based on a set of empirical correlations developed from a small database including 27 PAT characteristic curves. In addition, the methodology makes use of a CFD analysis of a single prototype PAT whose internal geometry is known to the authors. The first limitation of this analysis is the reliance on the CFD model of a single PAT, which may not be representative of the behavior of all the possible pumps available. Additionally, the methodology itself does not consider the real time flow and head variability typical of water networks, but rather works with average values. Finally, the lack of optimization of this method does not provide the users with a sense of how different turbine choices may result in different technical and economic project results (e.g., energy yield, payback time, $\mathrm{CO}_{2}$ emissions avoided) [28].

In a similar way, the methodology proposed by Stefanizzi et al. [29] gives the user a set of flow-head coordinates that can be employed to select a PAT from the pump-mode catalogues of a manufacturer, but with no indication of how robust the choice is. In fact, there is no optimization procedure and the only design parameter considered is the suitability of a PAT to work under the available flow and head conditions [29].

A recently published PAT selection method is the one proposed by Mitrovic at al. [30], which includes by design the variability of head and flow and is centered around an optimization algorithm to select the PAT according to different objective functions such as the maximization of energy recovery, maximization of the net present value (NPV) after 10 years, and the minimization of the payback period [30]. However, so far, this methodology has not been applied to a real-world installation but only compared theoretically against a 
few pre-existing methods. Furthermore, the accuracy of the method has been validated by comparing its results against a database of only 23 PAT characteristic curves collected from the literature [30].

In summary, the PAT selection method proposed here offers significant advantages over the existing ones available in the literature, namely:

- it can be applied practically by a hydro designer to select the model of PAT for a specific site from the catalogues of pump manufacturers;

- it considers by design the variability of flow and head conditions according to a HR regulation, which has been proven to be more flexible and efficient over an ER regulation [26];

- it allows the end user to visually select the final equipment layout according to the relative importance given to technical (e.g., the yearly energy yield) and economic parameters (e.g., payback time); and

- it has been applied to choose the equipment of an energy recovery installation, which was connected to the grid in late 2019 and whose performances have been monitored for a period of 13 months.

\subsection{Field Demonstration of the PAT Technology}

Despite the increasing number of scientific publications on PATs that have been produced in the last decade, the entirety of the available literature deals with various aspects of turbine performance and design, often supported by laboratory tests of one or more prototype units, and in some cases, the description of the nominal capacity of installed PAT schemes on drinking water networks. However, there is no publication up to date showing, at the same time, the applied PAT selection methodology and the performance over time of the selected turbines in a working PHP drinking water network environment. Chacón et al. [31] performed a similar analysis, however, they applied it to an irrigation water network that differs significantly from a drinking water one in terms of flow patterns and seasonality.

For instance, the details of a twin $5.5 \mathrm{~kW}$ MHP PAT installation in a Portuguese water network have been presented in the literature but with no mention of the design methodology used to select the precise model of the turbine nor the monitoring of the performances of the installation [32].

The only publication up to date that shows a limited set of measured performances of a $10 \mathrm{~kW}$ MHP PAT installation in a water network has the limitation of not mentioning how the design of the scheme and the selection of the PAT was performed [33]. Furthermore, the turbine cannot be considered as a full commercial installation since it was not connected to the grid, but rather the whole amount of generated electricity was dissipated via a resistor in the proximity of the powerhouse [33].

The authors of the present research believe that the lack of a detailed, robust, multidimensional, and proven PAT design methodology is a significant factor to explain the extremely limited applicability that the technology has found thus far, and that the realworld application of such a methodology in a PHP water network setting is a crucial step in accelerating the uptake of the technology more widely.

\subsection{Research Targets}

In order to facilitate the designer in the equipment choice, the objective of this research effort was the development of a software to allow for cross-comparison of suitable PAT choices for a determined site across different key decision parameters. In order to validate this software, it has been subsequently used to select the most appropriate PAT for a new PHP energy recovery scheme in an Irish rural water supply scheme. This pico-scale power plant was designed and built and put into operation in October 2019. Its performance has been monitored over a 13-month period, evaluating the compliance of power output with that predicted by the selection software. 


\section{Development of the PAT Selection Software}

The fundamental concept at the core of the software is the best efficiency point (BEP) of a PAT, described as the coordinates in terms of flow $\mathrm{Q}\left(\mathrm{m}^{3} / \mathrm{s}\right.$, unless otherwise stated) and head $\mathrm{H}(\mathrm{m})$ at which the device operates at peak hydraulic-mechanic conversion efficiency. The functionality of the software is described in the following sub-chapters and is summarized in Figure 1.

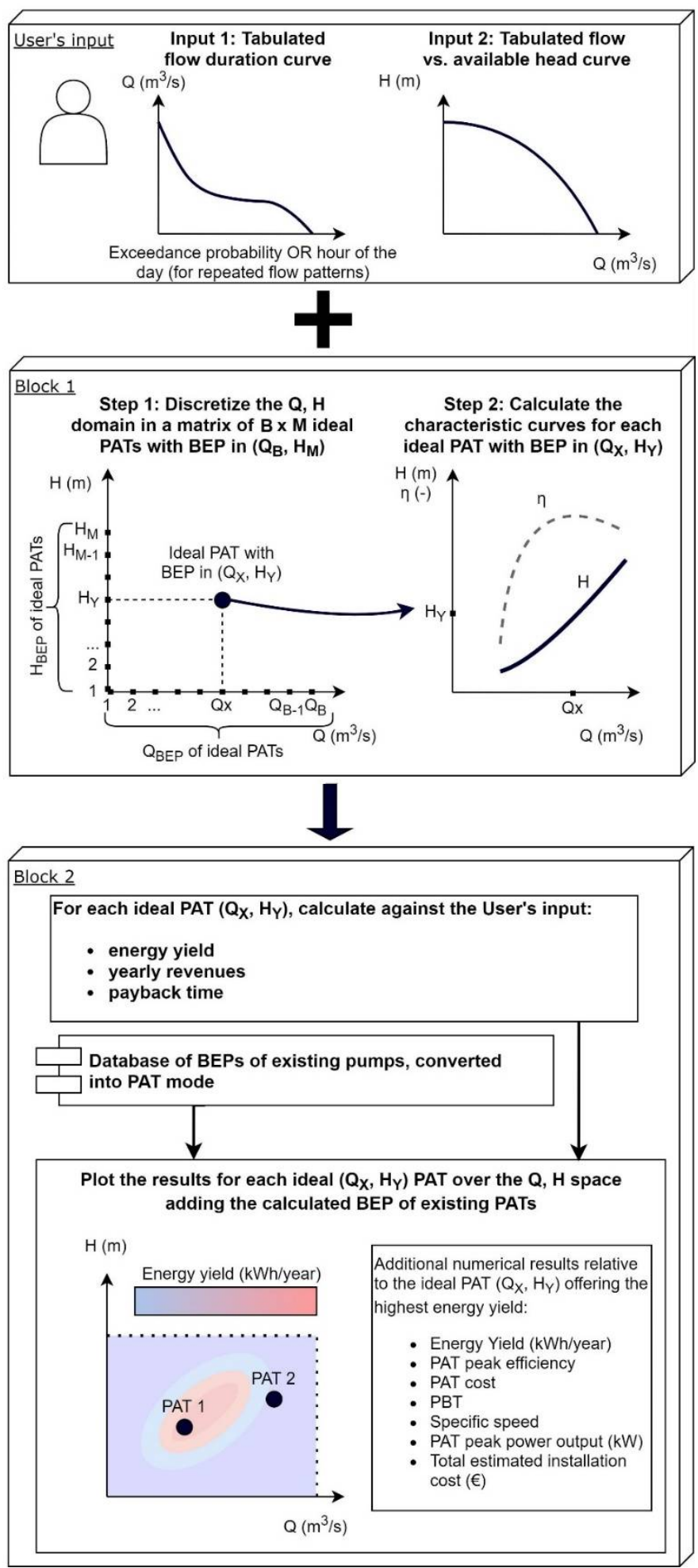

Figure 1. Schematic layout of the software logic. 


\subsection{Input Data}

The user of the software is expected to enter the desired speed of the turbine $(\mathrm{N})$ and two sets of data: the flow duration curve and the available head curve.

\subsubsection{Flow Duration Curve}

The flow duration curve represents the percentage of time along a typical year during which the flow rate available at the turbine will exceed a certain $Q$ value. Such a curve is derived by aggregating historical flow records at the same location and requires a large number of data points to ensure that it is an accurate representation of reality. In case the required amount of data is not available, if the site for which a PAT is being designed experiences a daily periodical flow rate profile oscillation, then the flow duration curve can be replaced by the 24-h flow profile. However, caution should be taken in the interpretation of the selection software results since such a daily profile would not capture occasional extreme flow variations (e.g., maintenance works or firefighting water flows) nor seasonal fluctuations in the average flow.

\subsubsection{Available Head Curve}

The available head curve represents the correlation between the flow rate $Q$ at the planned turbine site and the available head $\mathrm{H}$. Due to the presence of friction and local head losses along any pipe system, an increase in the flow will cause a decrease in the available head.

\subsection{Block 1 of the Software}

As a first step, the software creates a discretized Q-H domain in which each $\mathrm{Q}_{B}, \mathrm{H}_{M}$ coordinates corresponds to the BEP of an ideal PAT. Then, for each of these ideal PATs, the full characteristic curve at the selected speed $\mathrm{N}$ was estimated as well as the expected peak efficiency and purchase price. A number of methodologies exist within the literature, which can be adapted for this purpose, which are based either on experimental correlations or on machine geometry [34-40]. For the purpose of the present paper, the semi-empirical model proposed by Barbarelli et al. [28] was utilized and a $20 \%$ tolerance on the resulting BEP location was considered.

\subsection{Block 2 of the Software and Results Interpretation}

The second block of the software, as schematized in Figure 1, analyses the user's inputs and calculates the results in terms of expected yearly energy yield and simple payback time for all ideal PATs whose BEP lies in the $\mathrm{B} \times \mathrm{M}$ matrix. The software generates a $2 \mathrm{D}$ contour chart in which each point represents a hypothetical turbine whose BEP corresponds to the $\mathrm{Q}\left(\mathrm{m}^{3} / \mathrm{s}\right)$ and $\mathrm{H}(\mathrm{m})$ coordinates shown on the horizontal and vertical axis, respectively. At the same time, it shows which real-world off-the-shelf available PAT best approximates the optimal "ideal" PAT.

The software deals with the flow and head variability at a given site via HR, meaning that the turbine works at a fixed speed and any eventual surplus flow is bypassed and the eventual residual head is dissipated by an in-series valve.

The BEP, speed N, impeller diameter, and peak efficiency of over 400 centrifugal pumps (whose behavior as PATs has not been experimentally measured) were derived from the catalogues of various manufacturers and the prediction of their BEP as turbines was carried out by the software within Block 2, as shown in Figure 1. Additionally, the software includes a calculation of the expected installation cost, which considers the cost of the PAT and generator alone as $26 \%$ of the total project cost [41].

\subsection{Limits to the Applicability of the Software}

The present version of the PAT selection software only considers end-suction PATs despite the existence of several other families of pumps that can be used in turbine mode such as multistage, double-suction, and in-line types. However, the radial end-suction 
make is the most common in use worldwide and most of the equations built into the software have not been tested against different construction types.

Another limitation of the present software is that it considers fixed-speed PAT operations only, using an induction motor as a generator, which is a common choice for microand pico-hydropower installations either grid-connected or stand-alone [7].

\section{Design and Construction of the Pilot Plant}

\subsection{Overview}

The Blackstairs Group Water Scheme is a community-owned water network located in Co. Wexford, Ireland, whose geographical position and pipe layout are displayed in Figure 2. It supplies an average of $1500 \mathrm{~m}^{3}$ / day to 1072 clients through $117 \mathrm{~km}$ of water pipes (source: direct communication, 2017). It is served by a single water treatment plant (WTP) positioned at an altitude of $211 \mathrm{~m}$ a.s.l. that is fed via four separate supply lines of which one is pumped and the remaining three are gravity-fed. Among these, the supply line with the most pressure is a DN150 2-km long pipe conveying water from the source, in particular, the so-called "Connells intake".

The Connells intake is made up of three main components: a weir to slightly raise the level in the stream, a rough screening mesh, and a settling tank from where the DN150 supply line to the WTP departs. The precise altitude of the maximum water level within the settling tank was measured as $269.5 \mathrm{~m}$ a.s.l. via a GPS survey.

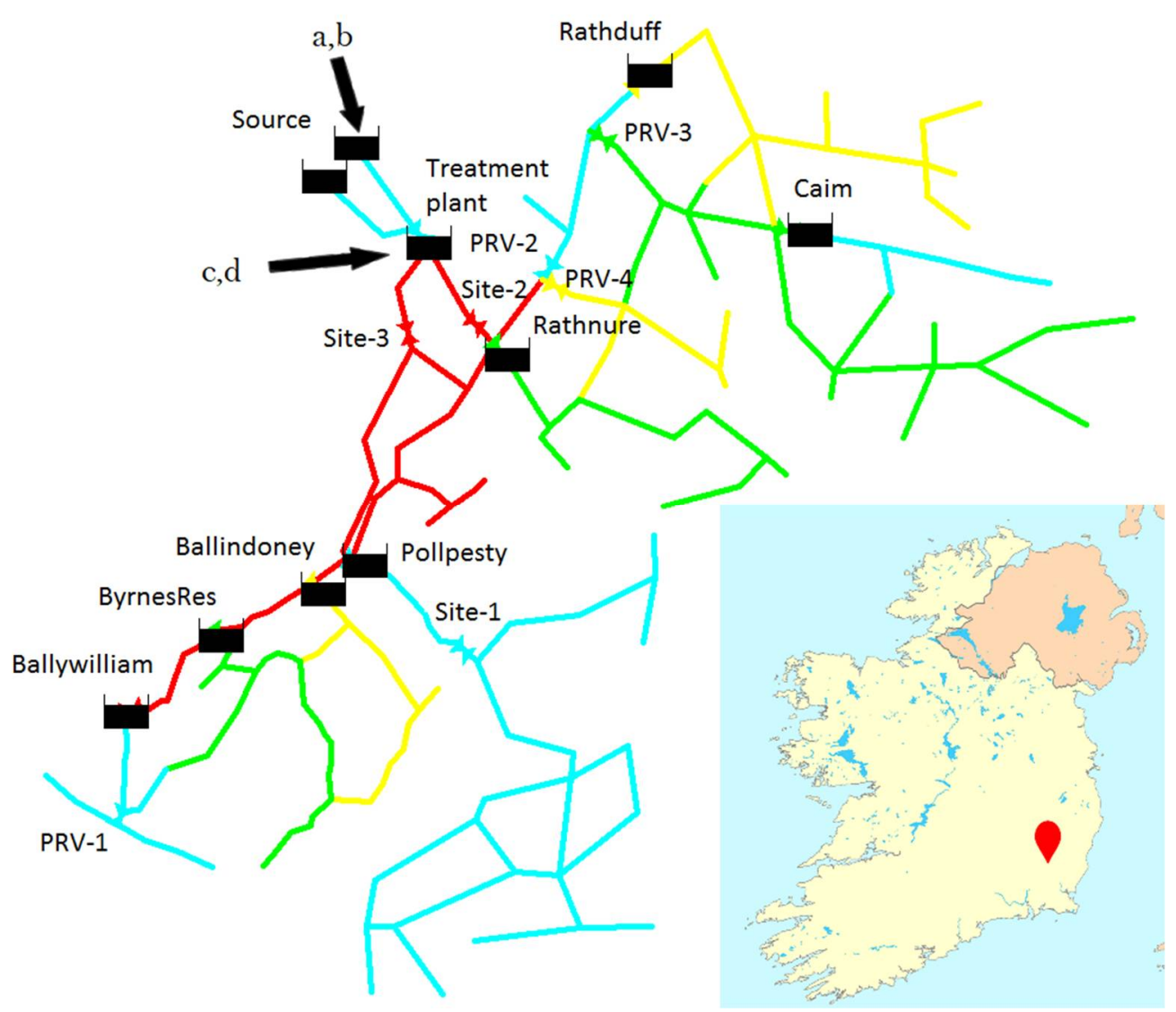

Figure 2. Simplified pipeline layout and geographical location of the Blackstairs Group Water Network in Ireland, with marked locations of items a,b,c,d described in Figure 3. Credits: Minestrone, public domain via Wikimedia Commons. 


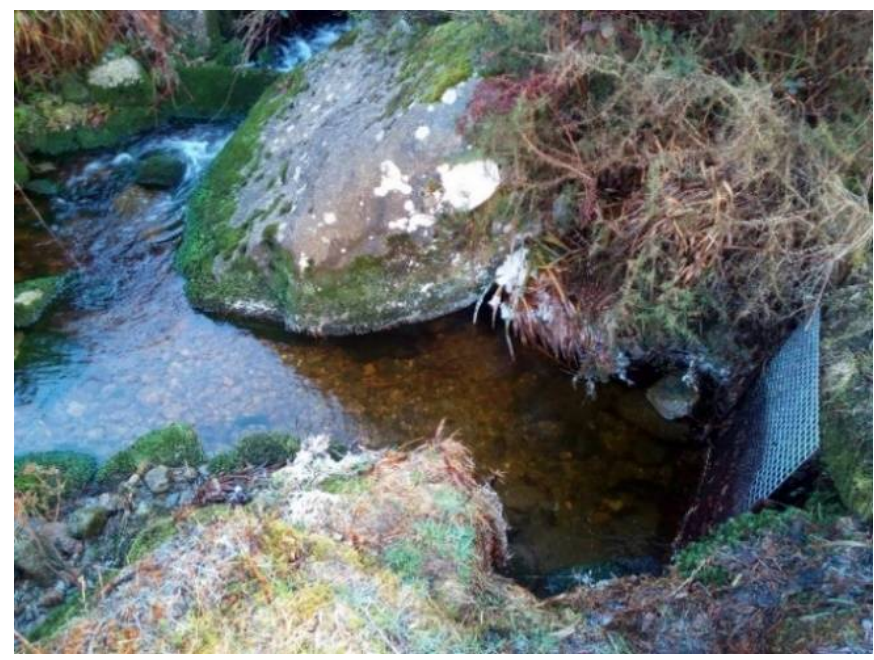

(a)

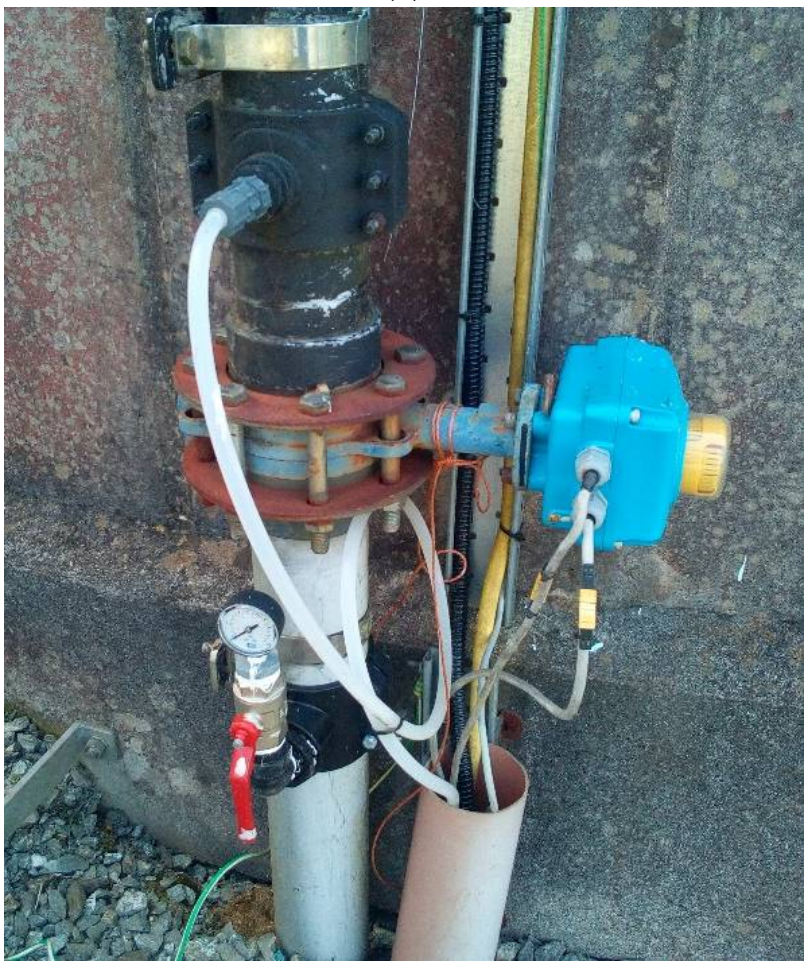

(c)

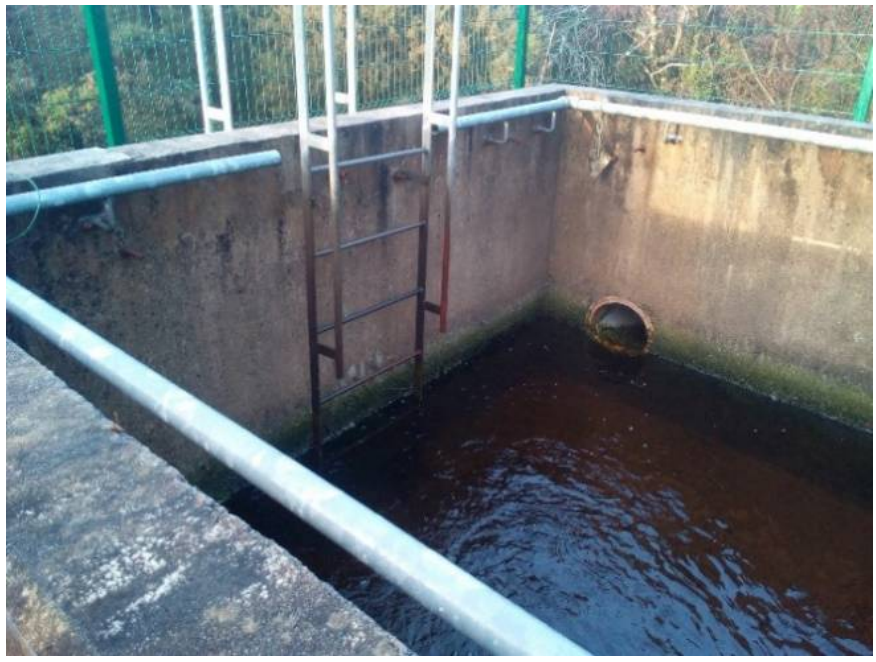

(b)

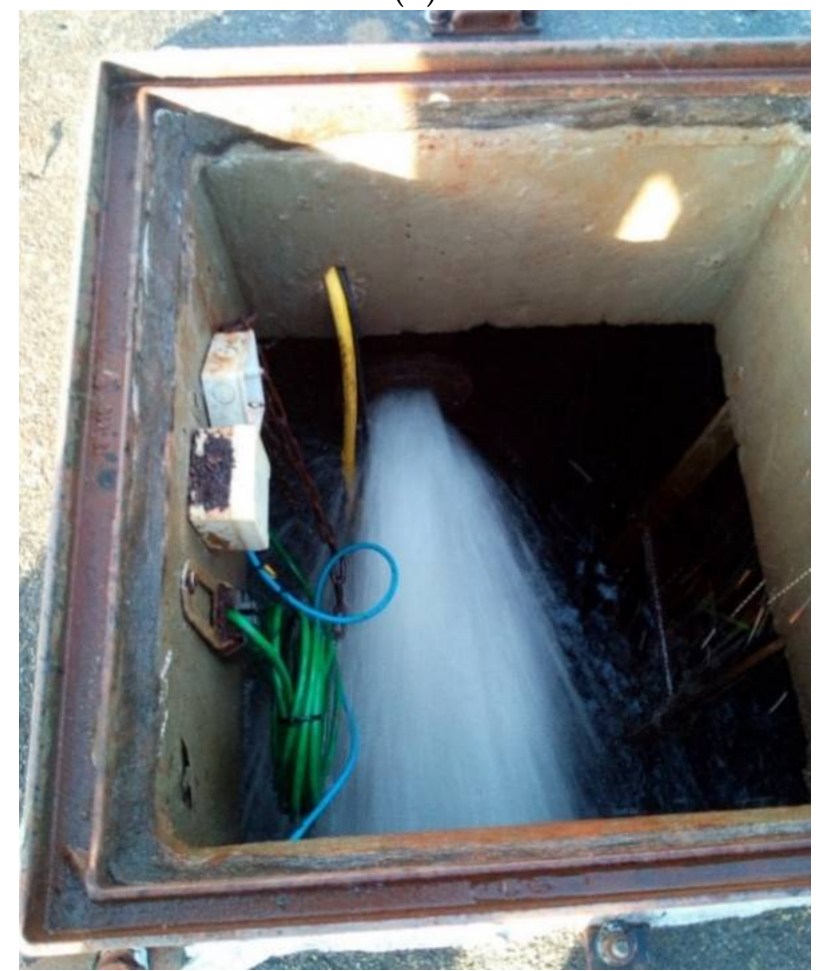

(d)

Figure 3. Portions of the Connells supply line. (a) River intake with screening mesh. (b) Settling tank at the start of the penstock. (c) The base of the raw water storage tank at the WTP, with visible on/off automated butterfly valve. (d) Water flow entering the tank.

At the terminal part of the same supply line is an on/off automated butterfly valve that regulates the inflow into a top-fed raw water tank according to the level of water in the tank itself. All the main elements of the water supply line whose relative location is shown in Figure 2 are displayed in Figure 3. Water in the raw water tank then undergoes treatment at the WTP before travelling onward to supply the network. In agreement with the WTP operator, it was decided to install a PAT energy recovery device just upstream of the raw water tank in a bypass of the existing on/off butterfly valve shown in Figure 3c.

\subsection{Design Data}

The key parameters to be fed into the PAT selection software, described in Section 2, are the available head and flow. 


\subsubsection{Water Flow Rate}

In the absence of hydrological data on the stream feeding the Connells intake, a flow meter was installed on the same supply line and readings were manually taken by the site maintenance staff between 12 March, 2018 and 8 June, 2018, as depicted in Figure 4. Each of the data points presented in Figure 4 corresponds to the manual reading from the flow meter display that the site maintenance staff took while entering the WTP and annotated on a paper register.

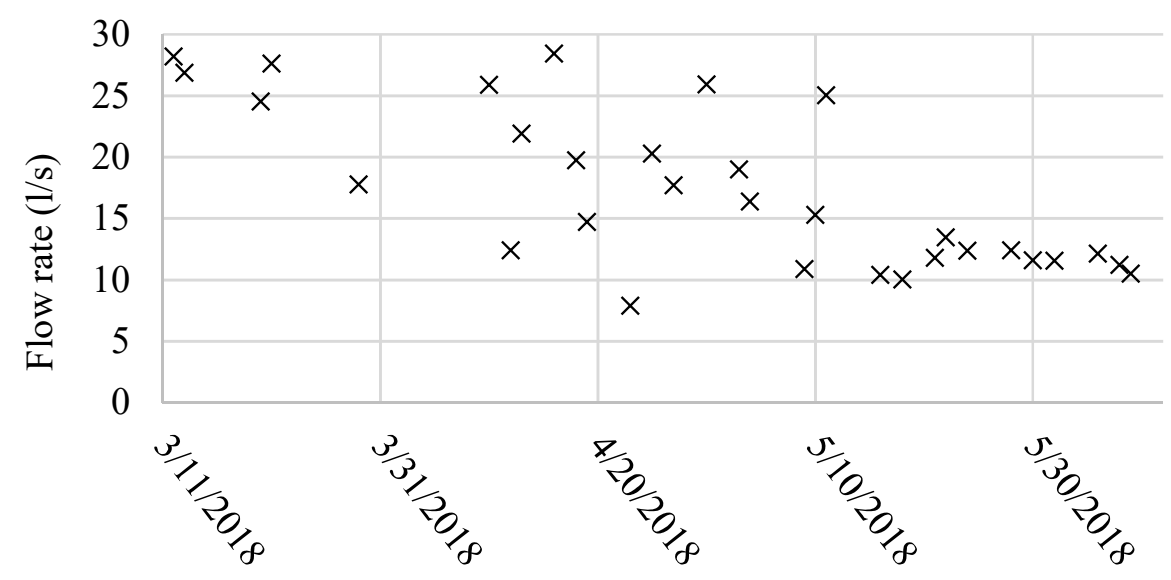

Figure 4. Recorded flow rates from the Connells intake.

The flow records shown in Figure 4 indicate that over the monitored period of time, there was a gradual drop in the flow, which was coherent with the reduced precipitation over May and June 2018. In fact, summer 2018 was marked by an abnormal heat wave and drought conditions that affected most of Ireland. In particular, 21 weather stations across the country recorded absolute drought conditions between 22 May and 14 July [42].

Discussions were also held with the WTP maintenance staff to ascertain that a usual flow minimum of $18 \mathrm{l} / \mathrm{s}$ was available at the intake during at least 10 months per year, while in the remaining two, corresponding to the summer dry season, the source river often dries up completely.

\subsubsection{Hydraulic Head}

The gross head was calculated as the difference between the elevation of the water level in the settling tank and the elevation of the top of the raw water tank, resulting in $55.65 \mathrm{~m}$. In order to compute the friction head losses in the pipeline, the Hazen-Williams empirical relationship was used:

$$
\mathrm{S}=\left(7.8828 \mathrm{Q}^{1.852}\right) /\left(0.7385 \mathrm{C}^{1.852} \mathrm{D}^{4.8704}\right)
$$

where $\mathrm{S}(-)$ is the slope of the energy line; $\mathrm{Q}$ is the flow rate $\left(\mathrm{m}^{3} / \mathrm{s}\right) ; \mathrm{C}(-)$ the HazenWilliams roughness coefficient; and $\mathrm{D}(\mathrm{m})$ is the internal diameter of the pipeline. After considering a pipeline length of $2 \mathrm{~km}$, a roughness coefficient of 100 [43] and a diameter D of $0.152 \mathrm{~m}$, the resulting head-flow relationship is shown in Figure 5.

At the same time, the gross hydraulic power available to be recovered by a turbine at this location after computing the effect of friction head losses has been computed as:

$$
P=\rho g H Q
$$

where $\mathrm{P}(\mathrm{W})$ is the power output; $\rho$ is the water density $\left(1000 \mathrm{~kg} / \mathrm{m}^{3}\right)$; $\mathrm{g}$ is the gravitational acceleration $\left(9.81 \mathrm{~m} / \mathrm{s}^{2}\right) ; \mathrm{H}(\mathrm{m})$ is the net available head; and $\mathrm{Q}\left(\mathrm{m}^{3} / \mathrm{s}\right)$ is the flow rate. The profile of resulting available power vs. flow rate is also displayed in Figure 5. 


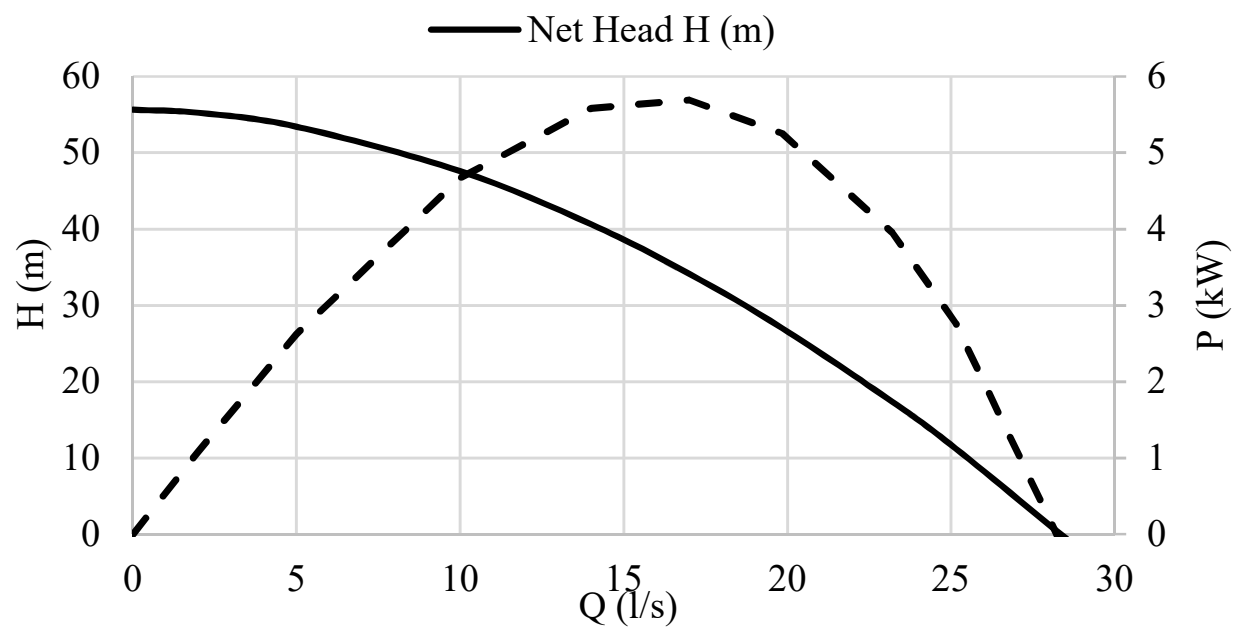

Figure 5. Net hydraulic head and theoretical available hydraulic power as functions of the flow rate.

The net hydraulic head profile depicted in Figure 5 is in good agreement with the recordings from the flow meter of Figure 4, showing a maximum attainable flow rate that can be conveyed through the pipeline of around $281 / \mathrm{s}$. At the same time, from the shape of the available power curve of Figure 5, it can be observed that the highest power output can be achieved with a flow of approximately $171 / \mathrm{s}$.

\subsubsection{Other Design Parameters}

Since the entirety of the electricity produced was intended for self-consumption by the WTP, whose typical load oscillates between 10 and $20 \mathrm{~kW}$, the value of the produced electricity corresponded to the price paid by the operator. The electricity price consists of a day rate of $€ 0.140 / \mathrm{kWh}$ and a night rate (9 h per day) of $€ 0.075 / \mathrm{kWh}$. Therefore, their average electricity rate for $24 \mathrm{~h}$ can be calculated as:

$$
(15 / 24) 0.140+(9 / 24) 0.075=0.115 € / \mathrm{kWh}
$$

After considering the applicable $13.5 \%$ reduced VAT, the final value of the electricity generated by the PAT was computed as:

$$
\mathrm{e}(€ / \mathrm{kWh})=0.115 \cdot 1.135=0.131 € / \mathrm{kWh}
$$

Finally, a further input parameter that had to be set into the software was the general value added tax (VAT) rate valid for Ireland, which applies to the cost of the equipment and civil works and corresponded to $23 \%$.

\subsection{Design and Construction}

\subsubsection{PAT Selection Software Inputs and Results}

After the findings described in Sections 3.2.1 and 3.2.2, the design flow duration curve to be fed into the software representing the amount of water available at the intake was selected as a constant $17 \mathrm{l} / \mathrm{s}$ flow for $83 \%$ of the time for a year, corresponding to 10 months out of 12 . Then, for the remaining $17 \%$ of time, the flow was considered to be zero, thus accounting for the expected summer drought conditions. The available head at such flow, calculated via the Hazen-Williams equation, as shown in Figure 5, was found to be equal to $34.13 \mathrm{~m}$. After entering these data into the software, and adding a turbine speed of $1520 \mathrm{rpm}$, an energy value of $0.131 € / \mathrm{kWh}$, and a VAT rate of $23 \%$, the calculations were performed, and the results are displayed in Figure 6. 


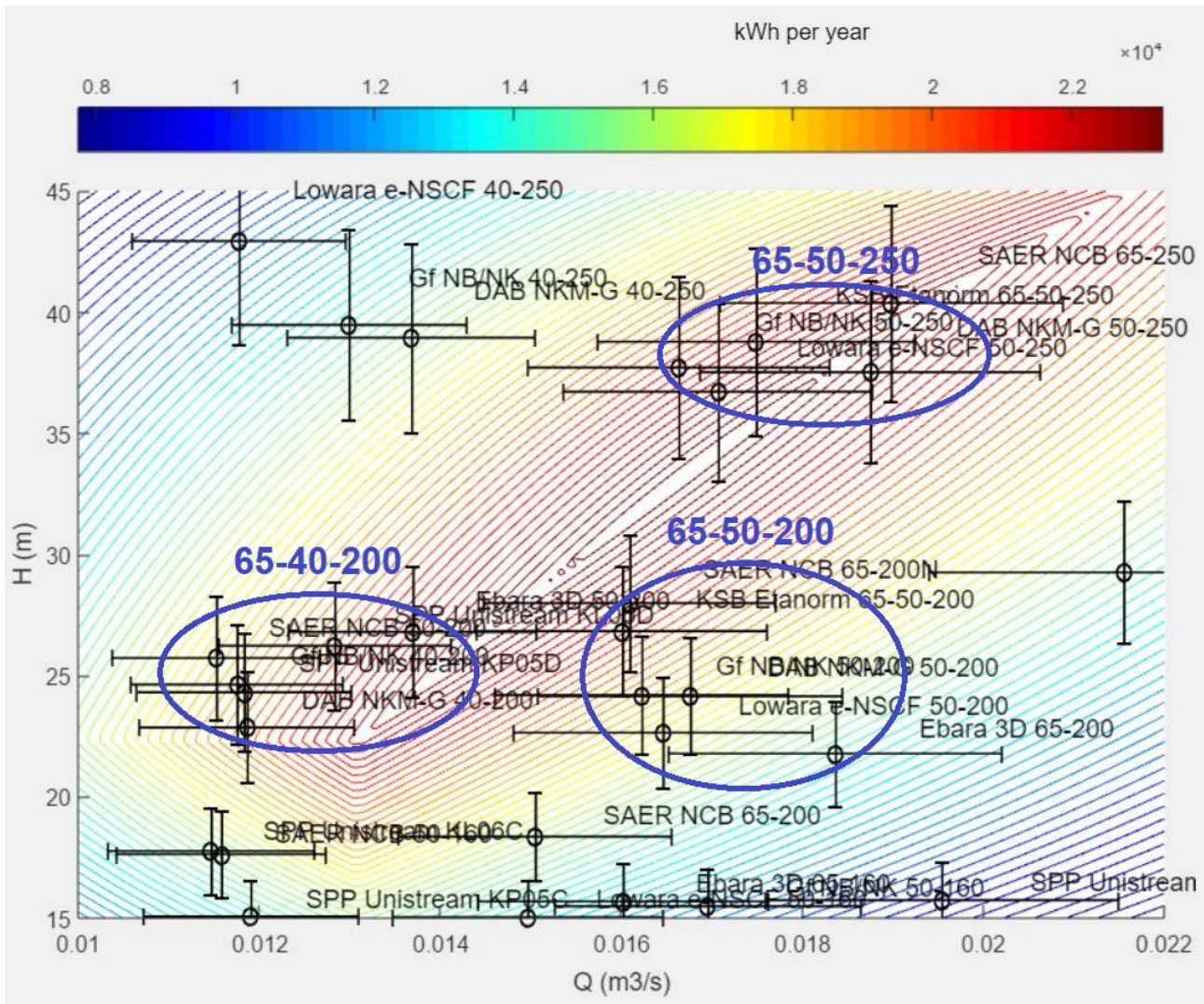

(A)

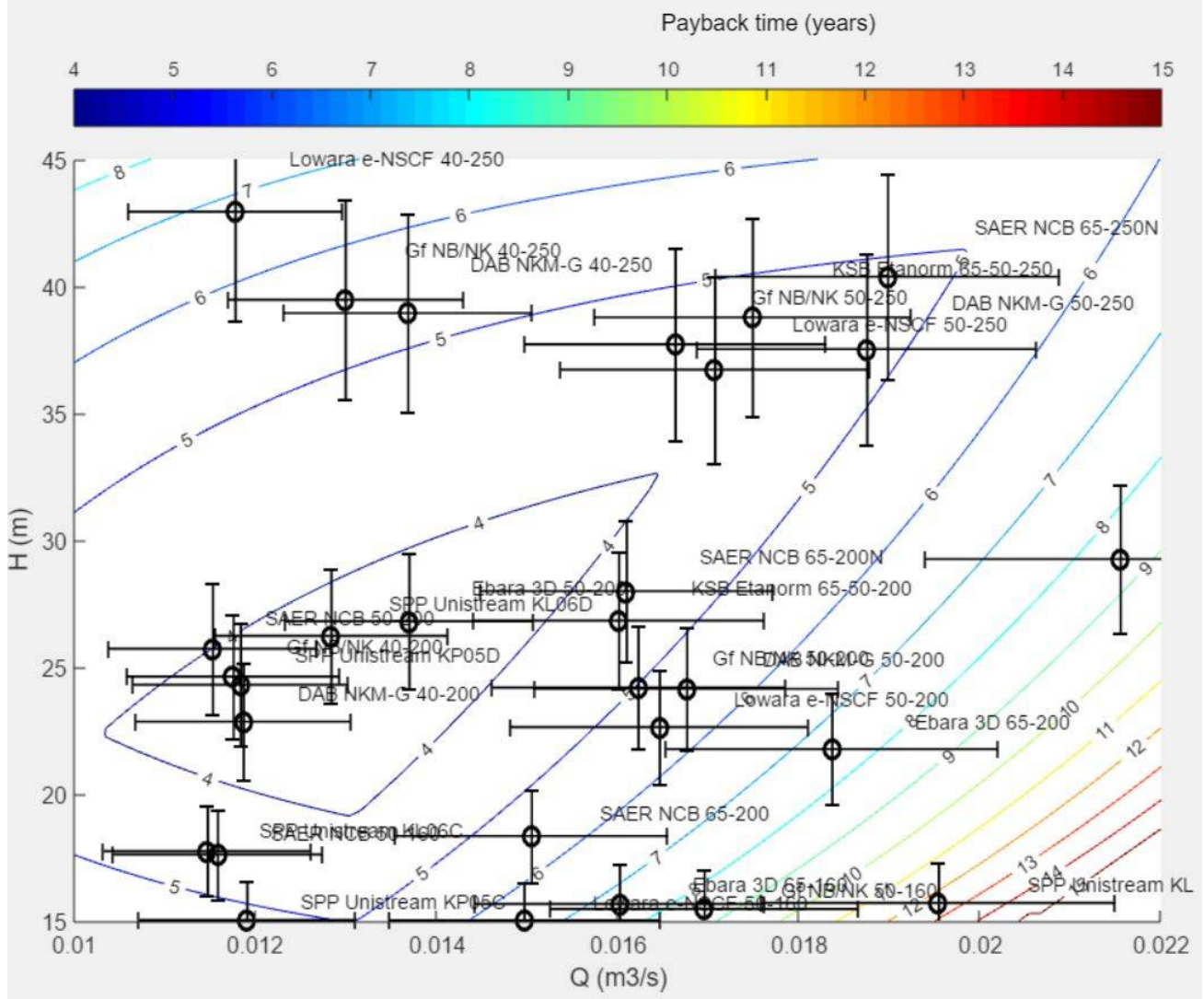

(B)

Figure 6. Cont. 


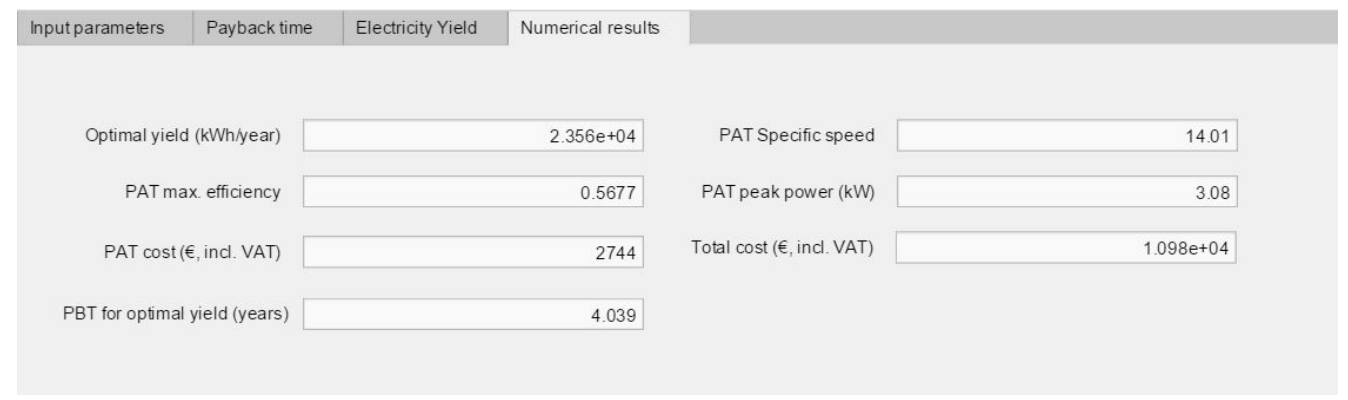

(C)

Figure 6. Results of the PAT selection software applied to the Connells supply line at Blackstairs WTP. (A) Expected yearly energy yield. (B) Expected payback time. (C) Summary of the numerical results.

In the $\mathrm{kWh}$ /year results shown in Figure 6A, points other than the design one $(\mathrm{Q}=17 \mathrm{l} / \mathrm{s}$ and $\mathrm{H}=34.13 \mathrm{~m})$ represent the amount of electricity that a theoretical PAT with $\mathrm{BEP}$ at any given $\mathrm{Q}$ and $\mathrm{H}$ coordinates is expected to generate under varying water availability conditions according to the set flow duration curve. At the same time, the error bands represent the $20 \%$ tolerance interval on the head and flow PAT prediction models as described in Section 2.2.

As seen in Figure 6A,C, the maximum energy yield $(23,560 \mathrm{kWh} /$ year) would be obtained by an ideal PAT with a BEP of $16.6 \mathrm{l} / \mathrm{s}$ and $33 \mathrm{~m}$. As seen in Figure 6C, such a PAT would cost around $€ 2700$ inclusive of VAT and generate up to $3.08 \mathrm{~kW}$.

Apart from a few outliers, the families of standardized PATs that offer the closest performances to the ideal one are the 65-50-250 (Figure 6A, top-right), the 65-40-200 (Figure 6A, bottom-left) and the 65-50-200 (bottom-center of Figure 6A). However, considering the uncertainty in the BEP determination shown as horizontal and vertical error bars in Figure 6A, it can be noted that the 65-50-250 family of standardized pumps is the safest choice since it sits on a wide plateau with an expected energy yield in excess of 20,000 kWh/year.

Regarding the variation in payback time, the results chart in Figure 6B indicates that the minimum payback time ( $<4$ years) would be obtained by choosing a 65-40-200 unit. However, selecting instead the larger 65-50-250 family, which maximizes the energy yield, would only cause an increase of the payback time to about five years.

\subsubsection{Design of the Energy Recovery Scheme}

After analyzing the software results described in Section 3.3.1, we decided to install a 65-50-250 PAT acting as an energy recovery device at the inlet of the raw water tank along the Connells intake line. The PAT would reduce the maximum flow that can be supplied via the pipeline to about $17 \mathrm{l} / \mathrm{s}$, while earlier, it could reach up to $281 / \mathrm{s}$, as seen in Figure 4, by causing additional head losses. However, this effect would be compensated by the fact that the PAT operates over $24 \mathrm{~h}$, thus changing from the current on/off regulation, which keeps the valve shut for more than $50 \%$ of time according to the daily tank level oscillations in the raw water tank. During times when the tank is full, the outflow from the PAT will be carried through the overflow pipe back into the source river.

For the sake of simplicity, the PAT was directly connected in parallel to the grid via a simple soft starter and thus would operate at a fixed speed of around $1520 \mathrm{rpm}$. The generator was selected as a $5.5 \mathrm{~kW} 400 \mathrm{~V} 3$-phase induction motor with four poles. The nominal generator size was chosen as $5.5 \mathrm{~kW}$ since Williams [7] suggests de-rating by at least a margin of $20 \%$ for induction motors when used as generators.

Further electric components necessary for the connection were an over-load fused protection and a grid interface relay certified for the EN50438 standard as required by Irish legislation for connection in parallel to a low-voltage grid [44]. 


\subsubsection{Construction and Commissioning}

The construction of the energy recovery scheme took place over four days spread between December 2018 and April 2019. The first start-up was performed on 18 April, 2019 but the PAT was eventually brought online on 7 October, 2019 after an additional automation was implemented through a request of the WTP operator in order to bypass the PAT in case of a low raw water tank level. The final installed PAT and electric and control panel are displayed in Figure 7.

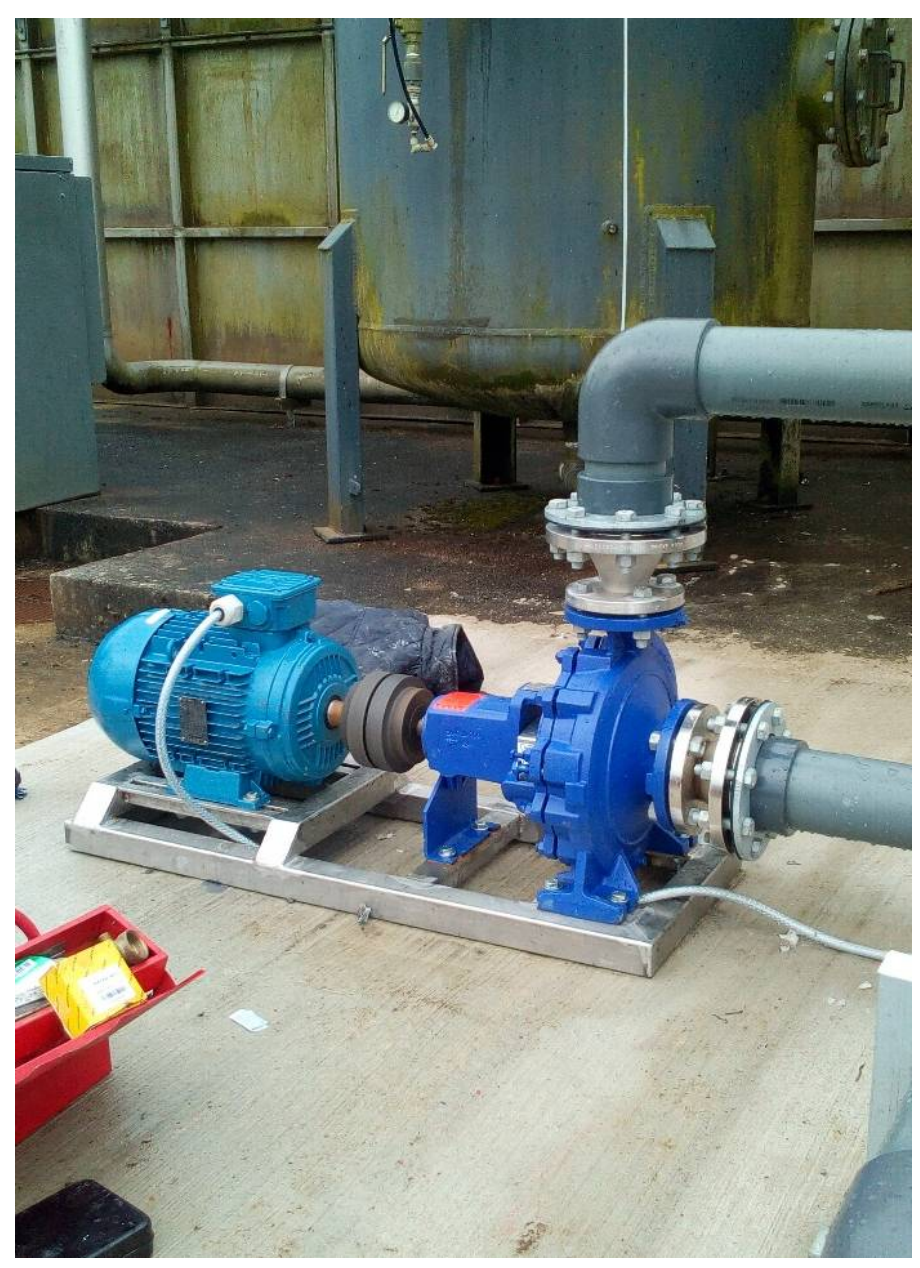

(a)

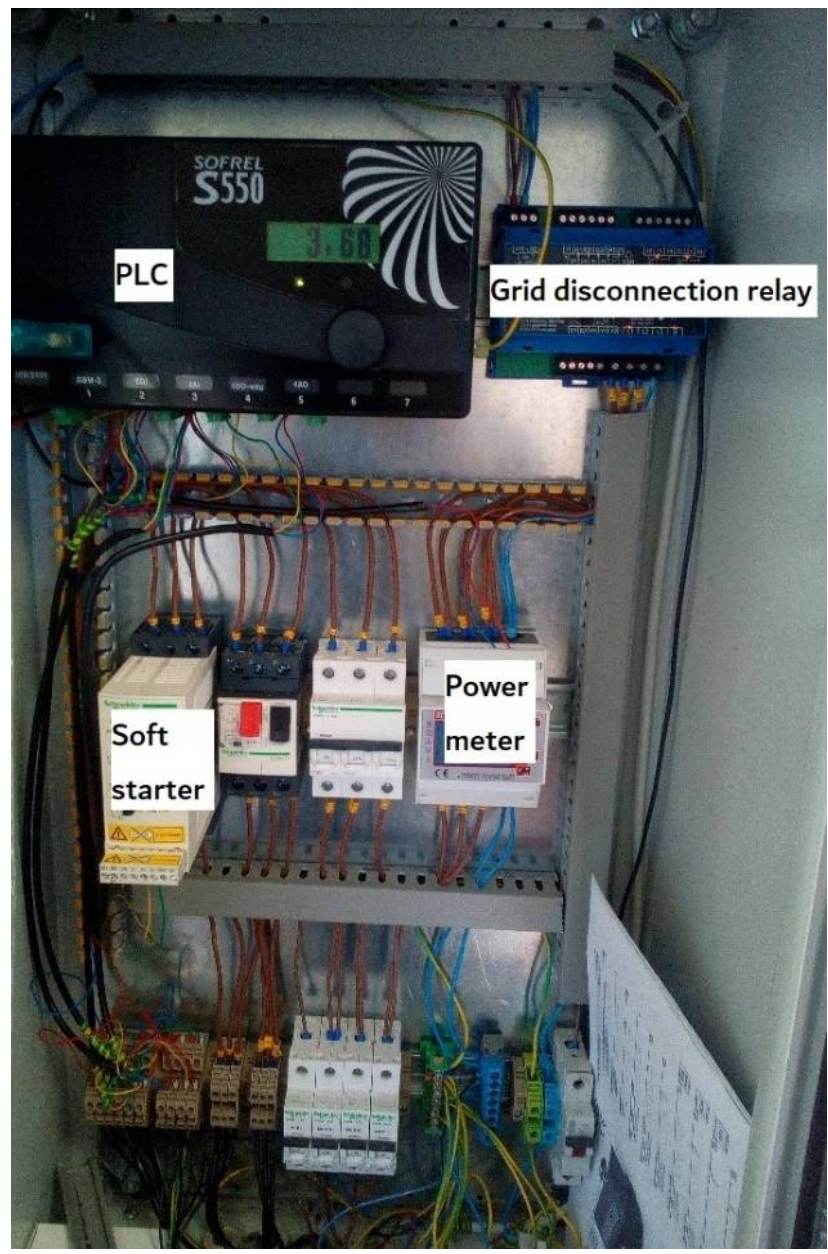

(b)

Figure 7. View of the installed energy recovery scheme. (a) PAT and generator. (b) Electric and control panel.

The total project cost including manpower corresponded to $€ 29,360$ inclusive of $23 \%$ VAT, comprising a remote monitoring device and associated flow and power meters that are non-essential costs for future installations. Given the experimental nature of the project, and partially due to the fact that the organizations involved in its construction had no previous experience with hydropower projects, the final costs ended up being significantly higher than the value predicted by the software. However, based on standard industry pricelists and including a fair compensation of the workforce involved, it is reasonable to consider a $€ 15,000$ all-inclusive cost for an identical novel installation.

\section{Performance Monitoring over 13 Months}

\subsection{Evaluation of PAT Characteristic Curve and Efficiency}

The instrumentation deployed to assess the performances of the PAT consisted of a MAG 5000 DN100 Siemens electromagnetic flow meter, an analog 0-10 bar Bourdon gauge to measure pressure, and a Sifam Tinsley AP 15-3DO three-phase power meter. 
The runaway flow rate and head of the PAT were measured in April 2019 before connecting the generator to the electric grid and were equal to $9.71 / \mathrm{s}$ and $45.5 \mathrm{~m}$, respectively. The first turbine start-up was performed on 18 April, 2019 and on that day, the unit generated a stable output of $2.93 \mathrm{~kW}$ with a flow of $15 \mathrm{l} / \mathrm{s}$ and head of $37.3 \mathrm{~m}$. A few weeks later on 2 May, 2019, the power output was $2.15 \mathrm{~kW}$ at a flow rate of $13.31 / \mathrm{s}$ and head of 32 $\mathrm{m}$. The recorded working points and runaway condition are plotted in Figure 8 against the PAT characteristic curve predicted by the software and the calculated system curve already displayed in Figure 5.

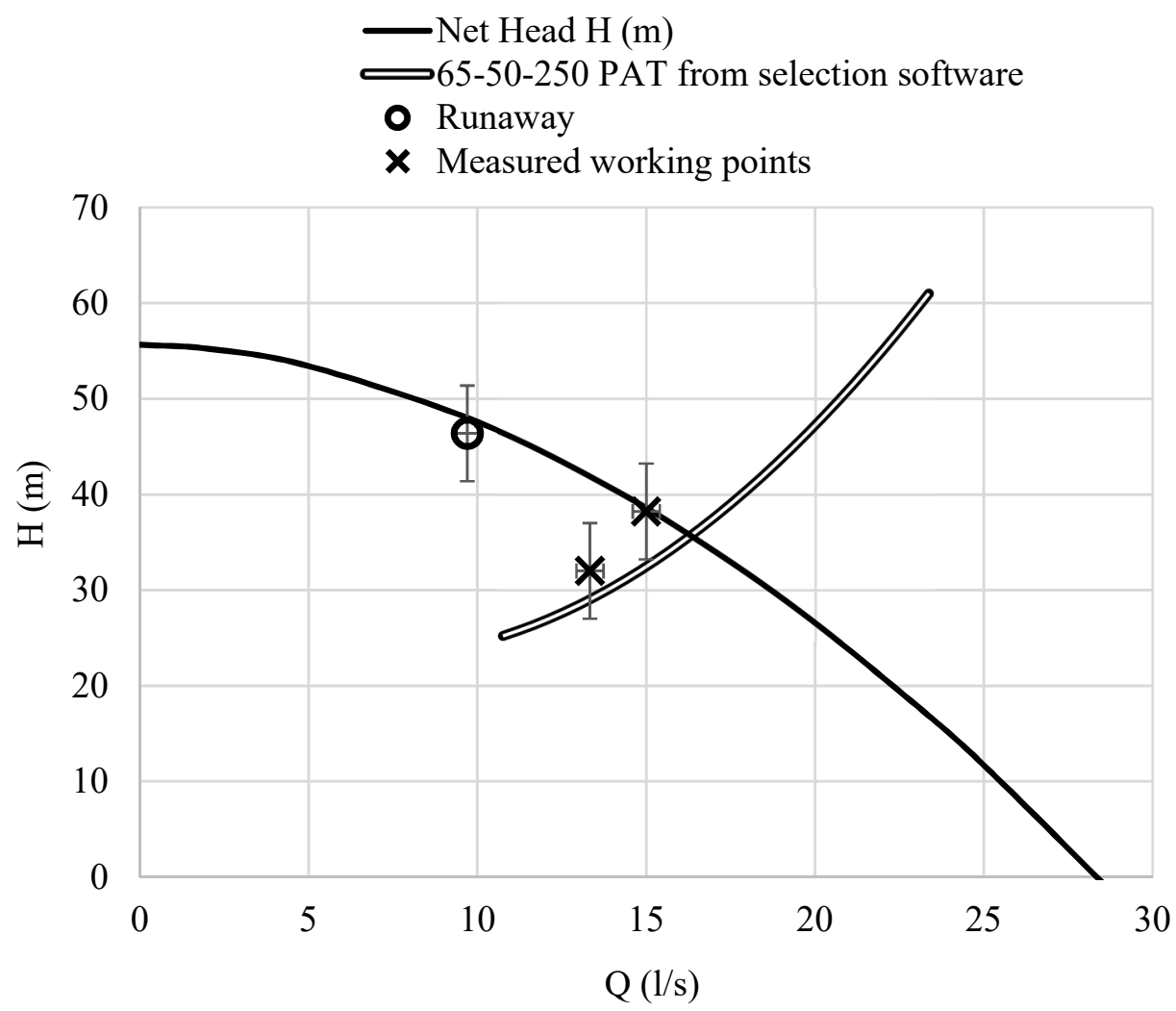

Figure 8. Recorded PAT working points and runaway compared to the calculated system curve and the turbine curve predicted by the selection software.

The difference between the measured PAT curve and the one predicted by the software, as shown in Figure 8, was minimal, as the relative distance between the predicted and the actual nominal working point was $-6.6 \%$ and $+8.5 \%$ in terms of flow and head, respectively. This confirms the validity of the algorithms embedded in the software, which lay behind the results of Figure 6.

Considering a generator efficiency of $86 \%$ as taken from the manufacturer's catalogue, the mechanical efficiency of the PAT was calculated as shown in Figure 9, where it was compared to the mechanical efficiency curve predicted by the selection software.

The power factor at the induction generator was measured to be in the range of $0.8-0.83$, which was deemed to be satisfactory since it compared favorably with the standard value of 0.8 . 
- - 65-50-250 PAT from selection software

X Measured working points

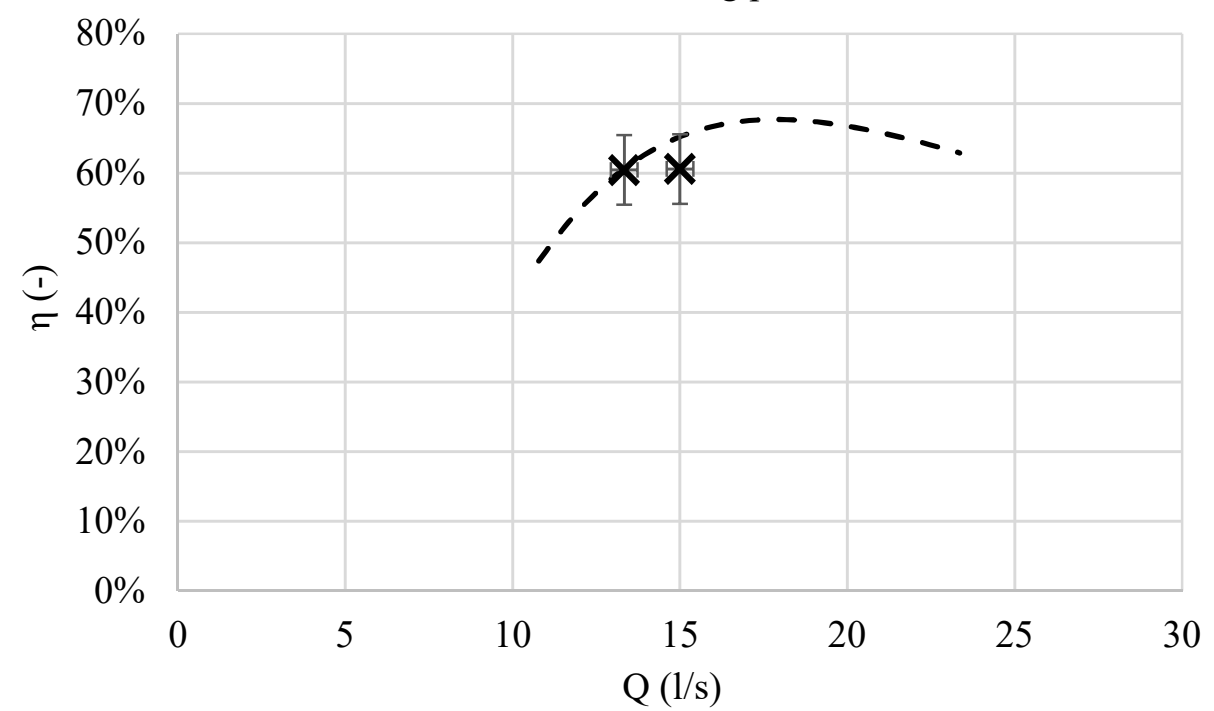

Figure 9. Recorded PAT mechanical efficiency compared to the one calculated by the selection software.

\subsection{Energy Output and Flow Rate over 13 Months}

The monthly energy production during the first 13 months of operations of the turbine are shown in Figure 10.

$\mathrm{kWh}$

2500

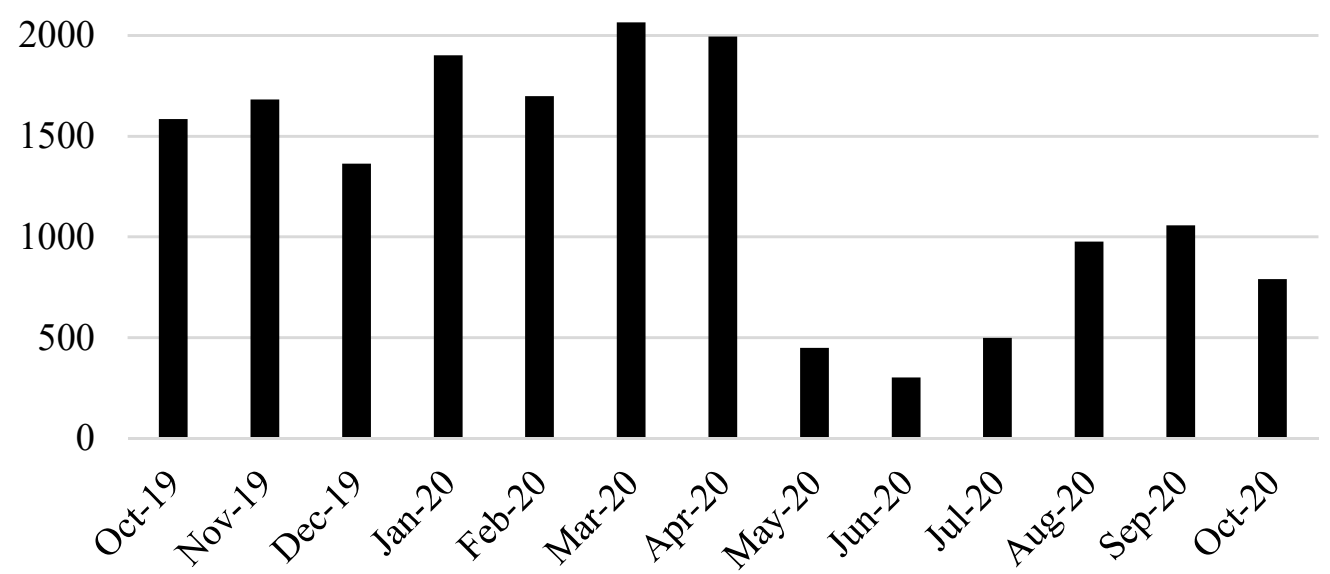

Figure 10. Monthly energy generation from the energy recovery PAT between October 2019 and October 2020.

As shown in Figure 10, over the first 12 months of operation, the PAT generated $15,559.12 \mathrm{kWh}$, which corresponded to $€ 2036.43$, according to the electricity value calculated through Equation (4). This was slightly lower than the predicted 21,000 kWh per year, as seen in Figure 6A, which was due to the dryer-than-usual 2020 spring period from May onwards. Additionally, since the flow duration curve used as an input, as described in Section 3.2.1, was not based upon a rigorous and time-consuming flow measurement campaign at the river intake, the flow duration curve entered in the software was only an approximative one. 
As shown in Figure 6B, the expected payback time of the overall energy recovery installation predicted by the software was slightly lower than five years, corresponding to a predicted overall installation cost of around $€ 12,000$. However, as mentioned in Section 3.3.3, the overall cost of such an experimental pilot installation ended up being far higher than the expected standard commercial costs.

\section{Discussion}

While there are many examples of technical and economic studies on the installation of PATs as energy recovery MHP devices within water pipelines in the literature, the complexity of the problem of selecting the most appropriate PAT for each installation has not been extensively addressed. In fact, such issues involve non-trivial trade-offs between technical and economic parameters such as energy recovery maximization and minimization of the payback time. Additionally, each end-user is likely to place a different value on each of the mentioned parameters, thus making the choice of equipment highly site-specific.

Therefore, decision support software has been developed in order to provide a robust tool able to assist the designer of an energy recovery installation in the selection of the most appropriate equipment set. The software requires the water flow and head conditions available at the site as input and is backed by a large database of off-the-shelf available pumps gathered from the manufacturer's catalogues. The main results from the software consist of a series of 2D contour charts showing the expected performances of existing PATs against a number of selected parameters (by default, yearly energy yield, and payback time). Such a tool has the potential of unlocking significant portions of the untapped hydropower potential in conduits, which could best be harnessed by means of PAT technology.

In order to provide validation, the software was applied to design a pico-hydropower energy recovery installation within an Irish rural water network with a peak power generation of about $3 \mathrm{~kW}$. A large number of potential pico-hydropower plant sites have been shown to exist in water pipe networks as well as a large number of potential microhydropower plant sites. Demonstration of the sustained performance of PAT installation in these locations is crucial to give confidence to water utilities and policy makers of the reliability, economic viability, and low-risk involved in installations of this kind, leading to greater exploitation and improved sustainability across the globe. The PAT selection software developed and demonstrated here highlighted that PAT installation can be realized within an accuracy range of $\pm 8.5 \%$.

The pilot scheme was subsequently built and put online in October 2019 and its performances have been monitored over a full year. The recorded data showed that the working curve of the PAT closely followed the one predicted by the software, while the yearly energy generation and relative energy savings were found to be lower by a factor of $26 \%$, which is likely due to a dry 2020 spring and the uncertainties in the flow duration curve used as input.

In regard to the power output of the built PAT pilot installation, it must be highlighted that it was negatively affected by the small diameter of the pre-existing DN150 supply pipe. In fact, at the design flow of $18 \mathrm{l} / \mathrm{s}$ over $25 \mathrm{~m}$ of hydraulic head, $45 \%$ of the total available head is dissipated as friction along the $2 \mathrm{~km}$ length of the pipe. However, had energy recovery been considered at the time of the design of the water network, the use of a larger DN250 pipeline would have reduced those losses to $2.2 \mathrm{~m}$, resulting in a doubling of the power output, approximately $6 \mathrm{~kW}$.

\section{Conclusions}

This paper highlights that the design and selection of PATs for water pipe network applications can be carried out by means of advanced selection software. The design of the selection software and resulting prediction accuracy achieved is related to the large number of measured PAT curves upon which it is based, the use of the state-of-the-art in 1D pump-PAT conversion methodologies, PAT curve extrapolation methodologies, and a large 
database of commercially available pump families from a variety of suppliers available on the market.

The use of the software to design a pilot PHP plant in a rural water network in Ireland showed that an economically viable PHP PAT installation could be achieved with good performance results over extended periods of time. The process of design and installation also highlights the importance of the accuracy of input parameters such as flow-duration curves and the experience of the installers for cost efficiency.

Author Contributions: Conceptualization, D.N. and A.M.; Methodology, D.N.; Software, D.N.; Formal analysis, D.N.; Writing—original draft preparation, D.N.; Writing—-review and editing, A.M.; Supervision, A.M.; Project administration, A.M.; Funding acquisition, A.M. All authors have read and agreed to the published version of the manuscript.

Funding: This work was supported by the ERDF Interreg Ireland-Wales Program 2014-2020 through the Dîr Uisce project (ref: 80910).

Institutional Review Board Statement: Not applicable.

Informed Consent Statement: Not applicable.

Data Availability Statement: Reported data available on request.

Conflicts of Interest: The authors declare no conflict of interest.

\section{Nomenclature}

$\begin{array}{ll}\text { C } & \text { Hazen-Williams roughness coefficient } \\ \text { D } & \text { Diameter }(\mathrm{m}) \\ \mathrm{e} & \text { Value of the electricity generated }(€ / \mathrm{kwh}) \\ \mathrm{H} & \text { Hydraulic head }(\mathrm{m}) \\ \mathrm{N} & \text { Rotational speed }(\mathrm{RPM}) \\ \mathrm{Ns} & \text { Specific speed }(-) \\ \mathrm{P} & \text { Power }(\mathrm{kw}) \\ \mathrm{Q} & \text { Flow rate }\left(\mathrm{m}^{3} / \mathrm{s}\right) \\ \mathrm{S} & \text { Slope of the hydraulic energy line }(\mathrm{m} / \mathrm{m}) \\ \text { Greek symbols } & \\ \eta & \text { Efficiency }(-) \\ \text { Abbreviations } & \\ 2 \mathrm{D} & \text { Two-dimensional } \\ \text { BEP } & \text { Best efficiency point } \\ \text { CFD } & \text { Computational fluid dynamics } \\ \text { DN } & \text { Nominal diameter } \\ \text { ER } & \text { Electric regulation } \\ \text { GPS } & \text { Global positioning system } \\ \text { HR } & \text { Hydraulic regulation } \\ \text { MHP } & \text { Micro-hydropower } \\ \text { NPV } & \text { Net present value } \\ \text { PAT } & \text { Pump as turbine } \\ \text { PBT } & \text { Payback time } \\ \text { PHP } & \text { Pico-hydropower } \\ \text { PRV } & \text { Pressure reducing valve } \\ \text { VAT } & \text { Value added tax } \\ \text { VOS } & \text { Variable operating strategy } \\ \text { WTP } & \text { Water treatment plant } \\ & \end{array}$




\section{References}

1. Novara, D.; Carravetta, A.; McNabola, A.; Ramos, H.M. Cost Model for Pumps as Turbines in Run-of-River and In-Pipe Microhydropower Applications. J. Water Resour. Plan. Manag. 2019, 145, 1-9. [CrossRef]

2. Mitrovic, M.A.D.; Crespo Chacon, M.; Garcia Morillo, J.; Rodriguez Diaz, J.A.; Adeyeye, K.; Ramos, H.M.; McNabola, A. Assessment of the Existing Energy Recovery Potential available in Drinking and Waste Water Networks in the Ireland and the UK, using Micro-hydropower. In Proceedings of the WATEF Network Conference, Bristol, UK, 2-4 September 2020.

3. Ramos, H.; Borga, A. Pumps as turbines: An unconventional solution to energy production. Urban Water 1999, 3, $261-263$. [CrossRef]

4. Spedaletti, S.; Rossi, M.; Comodi, G.; Salvi, D.; Renzi, M. Energy recovery in gravity adduction pipelines of a water supply system (WSS) for urban areas using Pumps-as-Turbines (PaTs). Sustain. Energy Technol. Assess. 2021, 45, 101040.

5. Moazeni, F.; Khazaei, J. Optimal energy management of water-energy networks via optimal placement of pumps-as-turbines and demand response through water storage tanks. Appl. Energy 2021, 283, 116335. [CrossRef]

6. Alatorre-Frenk, C. Cost Minimisation in Micro-Hydro Systems Using Pumps-as-Turbines. Ph.D. Thesis, University of Warwick, Coventry, UK, 1994.

7. Williams, A. Pumps as turbines for low cost micro hydro power. Renew. Energy 1996, 9, 1227-1234. [CrossRef]

8. Lahimer, A.; Alghoul, M.; Sopian, K.; Amin, N.; Asim, N.; Fadhel, M. Research and development aspects of pico-hydro power. Renew. Sustain. Energy Rev. 2012, 16, 5861-5878. [CrossRef]

9. McNabola, A.; Coughlan, P.; Corcoran, L.; Power, C.; Williams, A.P.; Harris, I.; Gallagher, J.; Styles, D. Energy recovery in the water industry using micro-hydropower: An opportunity to improve sustainability. Water Policy 2014, 16, 168-183. [CrossRef]

10. Jain, S.V.; Swarnkar, A.; Motwani, K.H.; Patel, R.N. Effects of impeller diameter and rotational speed on performance of pump running in turbine mode. Energy Convers. Manag. 2015, 89, 808-824. [CrossRef]

11. Polák, M. Innovation of Pump as Turbine According to Calculation Model for Francis Turbine Design. Energies 2021, 14, 2698. [CrossRef]

12. Novara, D.; McNabola, A. The Development of a Decision Support Software for the Design of Micro-Hydropower Schemes Utilizing a Pump as Turbine. Multidiscip. Digit. Publ. Inst. Proc. 2018, 2, 678. [CrossRef]

13. Singh, P. Optimization of Internal Hydraulics and of System Design for PUMPS AS TURBINES with Field Implementation and Evaluation; Dissertation, Universität Karlsruhe (TH): Karlsruhe, Germany, 2005.

14. Binama, M.; Kan, K.; Chen, H.-X.; Zheng, Y.; Zhou, D.-Q.; Su, W.-T.; Ge, X.-F.; Ndayizigiye, J. A Numerical Investigation into the PAT Hydrodynamic Response to Impeller Rotational Speed Variation. Sustainability 2021, 13, 7998. [CrossRef]

15. Hongyu, G.; Wei, J.; Yuchuan, W.; Hui, T.; Ting, L.; Diyi, C. Numerical simulation and experimental investigation on the influence of the clocking effect on the hydrau-lic performance of the centrifugal pump as turbine. Renew. Energy 2021, 168, 21-30. [CrossRef]

16. Capurso, T.; Stefanizzi, M.; Pascazio, G.; Ranaldo, S.; Camporeale, S.M.; Fortunato, B.; Torresi, M. Slip Factor Correction in 1-D Performance Prediction Model for PaTs. Water 2019, 11, 565. [CrossRef]

17. Morabito, A.; Vagnoni, E.; Di Matteo, M.; Hendrick, P. Numerical investigation on the volute cutwater for pumps running in turbine mode. Renew. Energy 2021, 175, 807-824. [CrossRef]

18. Plua, F.; Hidalgo, V.; López-Jiménez, P.; Pérez-Sánchez, M. Analysis of Applicability of CFD Numerical Studies Applied to Problem When Pump Working as Turbine. Water 2021, 13, 2134. [CrossRef]

19. Kocak, E.; Karaaslan, S.; Andrade-Campos, A.G.; Yucel, N. Energy recovery using pumps as turbines in water supply systems: A case study. In Proceedings of the Institution of Civil Engineers-Water Management, 16 September 2021; Thomas Telford Ltd: London, UK, 2021; pp. 1-28.

20. Lydon, T.; Coughlan, P.; McNabola, A. Pressure management and energy recovery in water distribution networks: De-velopment of design and selection methodologies using three pump-as-turbine case studies. Renew. Energy 2017, 114, 1038-1050. [CrossRef]

21. Fecarotta, O.; Aricò, C.; Carravetta, A.; Martino, R.; Ramos, H.M. Hydropower potential in water distribution networks: Pressure control by PATs. Water Resour. Manag. 2015, 29, 699-714. [CrossRef]

22. Ávila, C.M.; Sánchez-Romero, F.-J.; López-Jiménez, P.; Pérez-Sánchez, M. Definition of the Operational Curves by Modification of the Affinity Laws to Improve the Simulation of PATs. Water 2021, 13, 1880. [CrossRef]

23. Rossi, M.; Righetti, M.; Renzi, M. Pump-as-turbine for Energy Recovery Applications: The Case Study of An Aqueduct. Energy Procedia 2016, 101, 1207-1214. [CrossRef]

24. Corcoran, L.; McNabola, A.; Coughlan, P. Predicting and quantifying the effect of variations in long-term water demand on micro-hydropower energy recovery in water supply networks. Urban Water 2017, 14, 676-684. [CrossRef]

25. Carravetta, A.; Del Giudice, G.; Fecarotta, O.; Ramos, H.M. Energy Production in Water Distribution Networks: A PAT Design Strategy. Water Resour. Manag. 2012, 26, 3947-3959. [CrossRef]

26. Carravetta, A.; Del Giudice, G.; Fecarotta, O.; Ramos, H.M. PAT Design Strategy for Energy Recovery in Water Distribution Networks by Electrical Regulation. Energies 2013, 6, 411-424. [CrossRef]

27. Carravetta, A.; Del Giudice, G.; Fecarotta, O.; Ramos, H.M. Pump as Turbine (PAT) Design in Water Distribution Network by System Effectiveness. Water 2013, 5, 1211-1225. [CrossRef]

28. Barbarelli, S.; Amelio, M.; Florio, G. Using a Statistical-Numerical Procedure for the Selection of Pumps running as Tur-bines to be applied in Water Pipelines: Study Cases. J. Sustain. Dev. Energy Water Environ. Syst. 2018, 6, 323-340. [CrossRef] 
29. Stefanizzi, M.; Capurso, T.; Balacco, G.; Binetti, M.; Camporeale, S.M.; Torresi, M. Selection, control and techno-economic feasibility of Pumps as Turbines in Water Distribution Networks. Renew. Energy 2020, 162, 1292-1306. [CrossRef]

30. Mitrovic, D.; Morillo, J.G.; Díaz, J.A.R.; Mc Nabola, A. Optimization-Based Methodology for Selection of a Pump-as-Turbine in Water Distribution Networks: Effects of Different Objectives \& Machine Operation Limits on Best Effi-ciency Point. J. Water Resour. Plan. Manag. 2020. accepted for publication.

31. Chacón, M.C.; Díaz, J.A.R.; Morillo, J.G.; McNabola, A. Evaluation of the design and performance of a micro hydropower plant in a pressurised irrigation network: Real world application at farm-level in Southers Spain. Renew. Energy 2021, 169, 1106-1120. [CrossRef]

32. Ramos, H.M.; Samora, I.; Salqueiro, T.; Carriço, N.; Covas, D.; Monteiro, A. Intervention Concepts for Energy Saving, Recovery and Generation from the Urban Water System. 2014, pp. 182-209. Available online: https://riunet.upv.es/handle/10251/46628 (accessed on 25 October 2021).

33. Muhammetoglu, A.; Karadirek, I.E.; Ozen, O.; Muhammetoglu, H. Full-Scale PAT Application for Energy Production and Pressure Reduction in a Water Distribution Network. J. Water Resour. Plan. Manag. 2017, 143, 04017040. [CrossRef]

34. Derakhshan, S.H.; Nourbakhsh, A. Experimental study of characteristic curves of centrifugal pumps working as turbines in different specific speeds. Exp. Therm. Fluid Sci. 2008, 32, 800-807. [CrossRef]

35. Yang, S.S.; Derakhshan, S.; Kong, F.Y. Theoretical, numerical and experimental prediction of pump as turbine perfor-mance. Renew. Energy 2012, 48, 507-513. [CrossRef]

36. Tan, X.; Engeda, A. Performance of centrifugal pumps running in reverse as turbine: Part II-systematic specific speed and specific diameter based performance prediction. Renew. Energy 2016, 99, 188-197. [CrossRef]

37. Barbarelli, S.; Amelio, M.; Florio, G. Experimental activity at test rig validating correlations to select pumps running as tur-bines in microhydro plants. Energy Convers. Manag. 2017, 149, 781-797. [CrossRef]

38. Fecarotta, O.; Carravetta, A.; Ramos, H.M.; Martino, R. An improved affinity model to enhance variable operating strategy for pumps used as turbines. J. Hydraul. Res. 2016, 54, 332-341. [CrossRef]

39. Pugliese, F.; De Paola, F.; Fontana, N.; Giugni, M.; Marini, G. Experimental characterization of two Pumps As Turbines for hydropower generation. Renew. Energy 2016, 99, 180-187. [CrossRef]

40. Novara, D.; McNabola, A. A model for the extrapolation of the characteristic curves of Pumps as Turbines from a datum Best Efficiency Point. Energy Convers. Manag. 2018, 174, 1-7. [CrossRef]

41. García, I.F.; Novara, D.; Mc Nabola, A. A Model for Selecting the Most Cost-Effective Pressure Control Device for More Sustainable Water Supply Networks. Water 2019, 11, 1297. [CrossRef]

42. Met Éireann-Climatology and Observations Division. Summer 2018, An Analysis of the Heatwaves and Droughts that Affected Ireland and Europe in the Summer of 2018; Ireland, 2018. Available online: https:/ /www.met.ie/summer-2018-analysis (accessed on 25 October 2021).

43. Jaćimović, N.; Stamenić, M.; Kolendić, P.; Đorđević, D.; Radanov, B.; Vladić, L. A novel method for the inclusion of pipe roughness in the Hazen-Williams equation. FME Trans. 2015, 43, 35-39. [CrossRef]

44. ESB Networks. Connect a Micro-Generator. [Online]. Available online: https://www.esbnetworks.ie/new-connections/ generator-connections/connect-a-micro-generator (accessed on 6 April 2020). 